\title{
Attracting Young Talents to Manufacturing: A Holistic Approach
}

\author{
Stefano Perini ${ }^{1}$, Manuel Oliveira ${ }^{2}$, Joao Costa $^{3}$, and Dimitris Kiritsis ${ }^{4}$, \\ Poul Henrik Kyvsgaard Hansen ${ }^{5}$, Loukas Rentzos ${ }^{6}$, Afroditi Skevi ${ }^{4}$, \\ Hadrien Szigeti ${ }^{7}$, and Marco Taisch ${ }^{1}$ \\ ${ }^{1}$ Politecnico di Milano, Italy \\ \{stefano.perini, marco.taisch\}@polimi.it \\ ${ }^{2}$ SINTEF, Norway \\ manuel.oliveiradsintef.no \\ ${ }^{3}$ HIGHSKILLZ, Portugal \\ joao.costa@highskillz.com \\ ${ }^{4}$ Ecole Polytechnique Fédérale de Lausanne, Switzerland \\ \{dimitris.kiritsis,afroditi.skevi\}@epfl.ch \\ ${ }^{5}$ Aalborg University, Denmark \\ kyvs@business.aau.dk \\ ${ }^{6}$ University of Patras, Greece \\ rentzos@lms.mech.upatras.gr \\ ${ }^{7}$ Dassault Systémes, France \\ Hadrien.SZIGETIQ3ds.com
}

\begin{abstract}
In the last years, despite the global economic crisis, manufacturing is facing a serious difficulty in the recruitment of the brightest high-skilled human resources. National and international institutions have provided important guidelines to combat this skills mismatch and several innovations have been made both in STEM and manufacturing education. However, there is still a lack of concrete strategies harmonizing together delivery mechanisms and pedagogical frameworks throughout the whole student lifecycle. In order to mitigate these urgent needs, ManuSkills innovative approach provides a strong integrated strategy towards attracting young talent to manufacturing, by raising the awareness and providing the acquisition of new manufacturing skills. The keyconcepts and the strategy to achieve learning objectives are presented. Finally, ManuSkills Five Pillars, i.e. Interaction with the Experiments, Interaction with real companies, Social networks, Challenges and making real products, Career management and skills orientation, are explained in detail with the support of examples of application.
\end{abstract}

Keywords: manufacturing education, manufacturing skills, young talents, strategy.

\section{Introduction}

There are signs of timid improvement in the global economy where manufacturing plays a pivotal role. The persistent reports of skill shortages throughout the recession 
will only continue, and possibly escalate. Consequently, it has become of strategic interest for manufacturing industry to attract young talent, as also documented by a survey of over 400 CEOs all over the world managed by Deloitte and the U.S. Council on Competitiveness [1]. In fact, evidence suggests that manufacturing is facing more than other sectors an increasing difficulty in the recruitment of the brightest human resources [2]. This general difficulty seems to be clear taking into account also different perspectives, i.e.:

- the countries, facing high unemployment rate despite the increasing number of employers reporting difficulty in filling manufacturing jobs [3];

- the different functions within a single organization, with the engineering/technical ones among the most affected [4];

- the educational attainments, with a more critical shortage of high-skill and medium-skill workers rather than low-skill ones [5].

The above summary of indicators are just the tip of the iceberg concerning the problem of skill shortage in manufacturing, when one submerges beneath the surface, one encounters a more critical set of indicators related to young talent, which has been aptly designated as the STEM (Science, Technology, Engineering and Mathematics) leaking pipeline. This translates in the generalized disinterest of young students (i.e. both primary and secondary schools) in STEM and the disillusionment of young adults at universities leading to drop-outs. In fact, an analysis of the whole student lifecycle shows that the perception and feeling of the youngsters towards STEM is fundamental in order to form and stimulate their possible future involvement in the manufacturing world [6].

Therefore, strong actions are necessary to mitigate the challenge of attracting young talent to manufacturing. For instance, European Commission has supported it by providing guidelines to combat general skills mismatch [2], while the American Society of Manufacturing Engineers (SME) has profiled specific recommendations to solve the manpower crisis in manufacturing [7]. However, it is necessary to go beyond general guidelines, and conceive of more concrete strategies to attract young talent to manufacturing. In particular, there is a need for an integrated approach to harmonize together delivery mechanisms and pedagogical frameworks. Finally, these strategies need to be coordinated to support the students throughout their whole learning lifecycle. This means different actions are necessary across the STEM pipeline (i.e. children, teenagers, young adults), where in the early stages the focus should be on raising awareness towards manufacturing and in the later stages the focus should be the transformative deep learning of individuals, with reduced time-to-competence.

\section{Limitations in Current Approaches}

It is clear that the recruitment of young talents is crucial for the support and development of the manufacturing world. At the same time, it is evident that the harmonization between their demand and offer in a sector complicated also by the extreme need of multifaceted roles is becoming more and more difficult. Therefore, in this context, 
structural problems of lack of talents blend in with the need to prepare professionals able to face with success the new challenges of the Factory of the Future.

Pedagogical frameworks and learning theories have been widely addressed in literature, both as stand-alone concepts and taking into account the impact of ICT [8]. However, the contextualization to manufacturing remains largely amiss, although there has been an increase in effort to making STEM more engaging [9]. Some narrow, case in point, contextualized actions in manufacturing have carried out for children and teenagers, but mostly for testing purposes, as in the case e.g. of classroom immersion [10], computer aided systems [11], virtual design [12] and involvement of the students in visits to industrial plants [13]. For university students, there is more evidence of contextualized interventions, with plenty of studies concerning methods to engage students in manufacturing and improve the learning of advanced manufacturing skills. Despite the positive results achieved in the studies, the challenge remains concerning effective change and scale, thus illustrating the absence of a concerted approach to attracting young talent. The different efforts should be orchestrated and coordinated throughout the whole young talents pipeline, allowing the full exploitation of the existing contributions and enabling the continuous creation of innovative ones. Furthermore, it is necessary to collate information on the impact and effectiveness of the different approaches according to a wide range of indicators, such as age, theme, delivery mechanism, etc. Consequently, we believe the following key points should be taken into account:

- A child is faced with key decision points that affect his/her future career path. Because of the extreme complexity to define them from a psychological and evolutionary point of view (they can greatly vary from individual to individual) [14], a method is hence represented by their identification according to the concrete organization and timing of the different educational systems. For instance, a key decision point can be identified in this sense in the age group between 14 and 16 years, where important choices should be taken according to the differentiation occurring in the single educational systems;

- In most initiatives pertaining raising awareness in manufacturing, the impact is temporary and then the child may not be influenced by their past experience, which may have an important event but that would lose strength over time. It is necessary to provide more frequent experiences to young talent to remain positively influenced, thus each event renovates and reinvigorates results of the previous;

- There is evidence that the mainstream perception of manufacturing is antiquated and not aligned with reality, thus one way of changing this perception is by presenting to youngsters the latest trends in manufacturing. It is equally important to demonstrate the interdisciplinary knowledge and competencies required in manufacturing (e.g. digitalization, virtualization, servitization). 


\section{ManuSkills Approach}

The main aim of ManuSkills approach is to provide a strong integrated strategy towards attracting young talent to manufacturing, by raising the awareness and providing the acquisition of new manufacturing skills. With this aim in mind, the role of ICT in ManuSkills is twofold:

- it serves as enabler of the delivery of ManuSkills learning objects, by leveraging the mechanisms preferred by young talent of the generation of digital natives used to gaming, social media, experimentation and rich media;

- it provides the integration needed to collect and offer in a coordinate and efficient way different learning experiences in a gamified manner.

\subsection{ManuSkills Experiment}

Pivotal to ManuSkills is the concept of an Experiment, which consists of a selfcontained educational object conceived for a mixed ratio of creation/increase manufacturing awareness and of learning manufacturing skills. The actual contents of an educational object can be a simulation, video, serious game, animation, hands-on experiment to setup, etc. Consequently the meta-data of an Experiment consists of an Owner, Requirements, Delivery Mechanism, Content and Target Group.

\subsection{ManuSkills Target Groups}

Although ManuSkills addresses the entire student lifecycle, the creation of experiments is focused on two specific groups, i.e. Teenagers and Young Adults. This choice is rooted in three reasons:

- Focus the Experiments close to one of the most important key decision points of the student lifecycle of around 14-16 years old, i.e. when the different educational systems are differentiated in terms of curricula and types of schools;

- ManuSkills considers the "tweens", i.e. the youngsters between 10 and 12 years of age, that are too old to be children and too young to be teenagers. The reason being the pervasive misconceptions that affect the representative period before the key passage of the 14-16 years old but without deepening into the universe of children;

- ManuSkills considers "young talent" as the youngsters who have chosen a highlevel educational path and who are going to access the working world as highqualified professionals. This group is important due to the phase of disillusionment that leads to dropping out of the STEM pipeline, thus reducing the further the pool of young talent. 


\subsection{ManuSkills Learning Objectives}

ManuSkills applies different strategies for the learning objectives given to the two target groups:

- Teenagers: to drive and support the increase of their Awareness and Interest in manufacturing;

- Young Adults: to drive and support the increase of their Awareness, Interest and Application of manufacturing.

Awareness, Interest and Application represent the three different levels of communication and perception that are needed in order to efficiently involve the two Target Groups. These levels are inspired by Bloom's Taxonomy of Learning Objectives [15]. Bloom's taxonomy refers to a classification of the different objectives that can be set for students to define learning objectives. The lowest level of the Bloom's Taxonomy (remember) refers to basic knowledge: recalling facts, terms, and basic concepts. The second level (understand) refers to ability to understand facts and ideas by organizing, comparing, translating, and interpreting. The two upper levels refer to the ability to apply and use knowledge: application, analyze, evaluate, and create. Consequently, as indicated in Table 1, ManuSkills Learning Objectives reduce the Bloom's Taxonomy to only three levels:

Table 1. Mapping ManuSkills learning objectives to revised Bloom's taxonomy

\begin{tabular}{|c|c|}
\hline ManuSkills Learning Objectives & Revised Bloom's Taxonomy [16] \\
\hline Awareness & Remember \\
\hline Interest & Understand \\
\hline Application & Apply, Analyse, Evaluate, Create \\
\hline
\end{tabular}

When combining the ManuSkills Learning Objectives with the two Target Groups a matrix emerges. This matrix illustrates the challenges of targeting the two groups and fulfilling the Learning Objectives as depicted in Fig. 1.

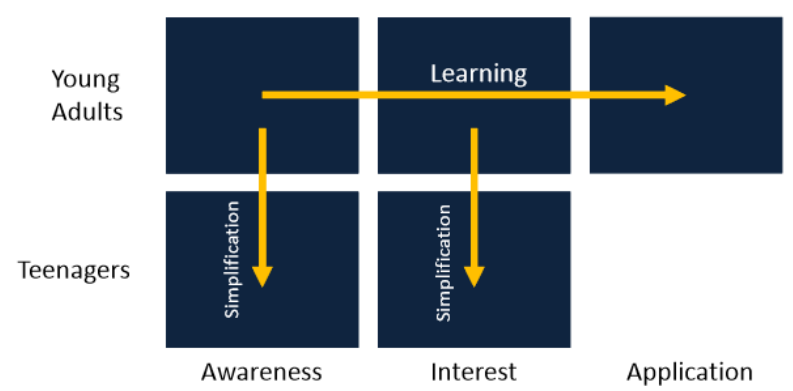

Fig. 1. Matrix of learning objectives strategy and target groups 
The challenges can be addressed individually one by one, e.g. how to create Awareness among Teenagers and how to create Awareness among Young Adults, etc. However, this would cause a huge effort and, therefore, ManuSkills approach highlights the importance of defining strategies based on a re-use of Delivery Mechanisms and Content among the different Target Groups and the different Learning Objectives.

\subsection{ManuSkills Five Pillars}

ManuSkills approach introduces five main pillars to follow in order to achieve the necessary impact in the targeted age groups:

1. Interaction with the Experiments: ManuSkills proposes the systematic use of innovative delivery mechanisms, integrated in an ICT platform that allows the dissemination of a wide range of Experiments, from very simple situations to complex challenges using professional manufacturing software. The platform requires a scientific approach in relationship with a curriculum of key subjects and skills to be taught. Each Experiment should bring awareness or understanding on welldefined key subjects, or let young adults apply well-defined manufacturing-related skills. Examples of Experiments are the creation of serious games to explain specific concepts and the development of simulations and quizzes to introduce manufacturing processes.

2. Interaction with real companies: ManuSkills identifies as fundamental the interaction of young talent with real companies, leveraging also the opportunity represented by the different Experiments. The interaction is essential in order to engage talents with living problems and situations also allowing manufacturing companies to extract interesting and innovative ideas in a continuous improvement perspective. Examples are the online living interaction between students and manufacturing engineers and the collection of feedbacks on students' work directly from manufacturing companies.

3. Social networks: Young talent should be involved by leveraging innovative distribution channels such as social media. The focused use of this kind of systems can capture with appealing situations the attention of the youngsters and enable more direct and up-to-date modalities of interaction among the different stakeholders. Examples are the collection of feedbacks from students by means of social network features and the creation of forums for the discussion of specific manufacturing themes.

4. Challenges and making real products: Another important aspect is for young talent to have realistic and scenario-based challenges. Both creation of awareness and development of skills benefit from the anticipated exposition to real-world problems, such as the design of real products. This aspect will further improve the needed relationship among youngsters, schools, universities and manufacturing companies. Examples are the creation of incubators to allow students to prototype their ideas and the definition of contests among students based on the improvement of an everyday product. 
5. Career management and skills orientation: Finally, the career management and skills orientation aspects of ManuSkills supports all the other Pillars. This strong effort will help in communicating to the young audience the real essence of manufacturing, allowing the creation of a real and authentic perception of what modern manufacturing is and will be. Examples are the possibility for students to show their talent by means of the platform and the use of engaging ways to present career options in manufacturing online.

\section{Conclusions and Next Steps}

In this paper, the big issue of attracting young talents to manufacturing is clearly introduced and explained in all its aspects. The available approaches trying to support its solution, both involving and not involving ICT technologies, are reviewed. Therefore, the lack of a holistic approach providing an integrated solution to the problem is highlighted. In this respect, the innovative ManuSkills approach is presented, outlining a concrete strategy that takes into account three fundamental requirements for the success of such kind of concept, i.e. the focus on the key-decision points of the student lifecycle, the correct timing of the different actions to implement and the priority given to youngsters following a high-level educational path. The strategy to involve the two Target Groups identified (i.e. Teenagers and Young Adults) by means of three different levels of communication and perception, i.e. Awareness, Interest and Application, is explained. Finally, the five Pillars of ManuSkills approach to support the development of coordinated actions for the attraction of young talents to manufacturing and their deep learning of manufacturing skills is presented. The main Pillars identified are Interaction with the Experiments, Interaction with real companies, Social networks, Challenges and making real products, Career management and skills orientation. For each of them, proper examples of application are given.

The next steps will be the finalization of ManuSkills ICT platform and of the related Experiments. The different Experiments developed will be subsequently tested in different scenarios with the aim of collecting precious feedbacks from users belonging to the two Target Groups. Further findings will be hence properly used also for the empowerment and refinement of the presented ManuSkills approach in a continuous improvement perspective.

Acknowledgements. The research leading to these results has received funding from the European Community's Seventh Framework Programme (FP7/2007-2013) under grant agreement $\mathrm{n}^{\circ} 609147$.

\section{References}

1. Deloitte U.S. \& the Council on Competitiveness, Global Manufacturing Competitiveness Index (2013)

2. European Commission, Employment and Social Developments in Europe 2012 (2013) 
3. World Economic Forum, The future of manufacturing - Opportunities to drive economic growth (2012)

4. Economist Intelligence Unit, Plugging the skills gap - Shortages among plenty (2012)

5. McKinsey \& Company, Manufacturing the future: The next era of global growth and innovation (2012)

6. Manufacturing Institute, Roadmap to education reform for manufacturing (2010)

7. Society of Manufacturing Engineers, Workforce imperative: a manufacturing education strategy (2012)

8. Klein, H., Noe, R., Wang, C.: Motivation to learn and course outcomes: The impact of delivery mode, learning goal orientation, and perceived barriers and enablers. Personnel Pscyhology, 665-702 (2006)

9. Patterson, D.: Student Awareness and Career Motivation in the STEM Fields. Northwest Association for Biomedical Research (2011)

10. Fralick, B., Kearn, J., Thompson, S.: How Middle Schoolers Draw Engineers and Scientists. Journal of Science Education and Technology, 60-73 (2009)

11. Ziemian, C., Aument, J., Whaley, D.: Manufacturing Technology in Middle School Classrooms: A Collaborative Approach. In: International Conference on Engineering Education, ICEE, Coimbra, Portugal (2007)

12. Howard, M., Washington, N., Shurn, T., Brge, L., Warner, G.: The Tricked-Out Virtual Body Shop: Recruiting African-American High-School Students to STEM through Automotive Design (2011)

13. Prins, R., MacDonald, S., Leech, J., Brumfield, J., Ellis, M., Smith, L., Shaeffer, J.: Techfacturing: A Summer Day Camp Designed to Promote STEM Interest in Middle School Students through Exposure to Local Manufacturing Facilities. In: ASEE Southeast Section Conference (2010)

14. Osborne, J., Dillon, J.: Science Education in Europe: Critical Reflections. King's College, London (2008)

15. Bloom, B.S., Engelhart, M.D., Furst, E.J., Hill, W.H., Krathwohl, D.R.: Taxonomy of educational objectives: The classification of educational goals. David McKay Company, New York (1956)

16. Anderson, L.W., Krathwohl, D.R., Airasian, P.W., Cruikshank, K.A., Mayer, R.E., Pintrich, P.R., Raths, J., Wittrock, M.C.: A taxonomy for learning, teaching, and assessing: A revision of Bloom's taxonomy of educational objectives. Allyn and Bacon (2000) 